\title{
Don't cry for me Britannia: The Resilience of the European Union to Brexit
}

Narisong Huhe, School of Government and Public Policy, University of Strathclyde, Glasgow, UK

Daniel Naurin, Department Public and International Law, University of Oslo, Oslo, Norway and Department of Political Science, University of Gothenburg, Gothenburg, Sweden

Robert Thomson, School of Social Sciences, Monash University, Melbourne, Australia

\begin{abstract}
We assess the impact of the United Kingdom's 2016 decision to leave the European Union on the Council of the EU, where Brexit is likely to have the clearest observable implications. Using concepts and models from the spatial model of politics and network analysis, we formulate and test expectations regarding the effects of Brexit. We examine two of the most prominent datasets on recent decision-making in the EU, which include data on cooperation networks among member states before and after the 2016 referendum. Our findings identify some of the political challenges that Brexit will bring, but also highlight the factors that are already helping the EU's remaining member states to adapt to Brexit.
\end{abstract}

Keywords: Brexit, Council, bargaining, networks, legislation.

Corresponding author: Robert Thomson, School of Social Sciences, Monash University, Melbourne, VIC3800, Australia. Email: robert.thomson@monash.edu 
What impact will Brexit have on the decision-making processes and outputs of the European Union (EU)? Much has been written about the causes of Brexit and its possible effects on the United Kingdom (UK) and the economic relations between the UK and the EU27 (e.g. Armstrong, 2018; Gamble, 2018; Steenbergen and Siczek, 2017). However, there has been little systematic analysis of the possible effects of Brexit on the functioning of EU institutions. Losing one of its largest member states - in terms of the size of the UK's population, economy, diplomatic resources and military power - could have important consequences for the policies that the EU will adopt and for the relations among the remaining states. This is particularly plausible with respect to the Council of the EU, the primary intergovernmental institution in EU decision-making, and the part of the EU system on which we focus.

Our study presents comparative quantitative analyses of recent evidence on decisionmaking and cooperative relationships among member states. For the most part, the few existing studies of the impact of Brexit on the EU rely on qualitative syntheses of expert opinions. For instance, Jacobs (2018: 73) posits that Brexit could have a range of significant consequences for the power relationships among the remaining EU27, including the possibility of reinforcing the power of Germany. He further notes that the consequences of Brexit, while potentially significant, are unclear for most of the remaining states. Similarly, Krotz and Schild's (2018) recent study of the effects of Brexit on Franco-German bilateralism presents three contrasting scenarios, which include German hegemony, the decline of the European project and a rejuvenated Franco-German tandem. An earlier study by Möller and Oliver (2014; see also Oliver, 2016) offers a range of perspectives from other countries, including some of the remaining EU27 states. While these contributions are informative, they illustrate the wide range of expert opinion on this matter. Moreover, the evidence and theories that support their conclusions are often unstated. 
Our analyses assess the emerging impact of Brexit by integrating two established approaches to research on the EU's legislative process. The first approach is based on the spatial model of politics, in which actors' policy positions are represented as points on one or more conflict dimensions. The spatial model has been used to formulate and test a broad range of rational choice institutional theories of the EU's decision-making process, including theories that focus on formal legislative procedures (e.g. Crombez, 1996; Steunenberg, 1994; Tsebelis and Garrett, 2000), and informal bargaining (e.g. Achen, 2006; Bueno de Mesquita and Stokman, 1994). We use the dataset from the Decision-making in the EU (DEU) project, which includes information on EU actors' policy positions on controversial legislative proposals that were on the agenda in the period 2004-2008, before the prospect of Brexit arose. Comparisons of member states' policy positions in these data with their policy positions in previous periods reveal a significant degree of stability (e.g. Thomson, 2011). While we cannot know if member states' policy positions will be similar in the future, the stability of these data in the past indicates that they provide an informative basis for assessing the impact of Brexit. In the first step in our analysis, we apply a bargaining model, which in previous work generated the most accurate forecasts of decision outcomes (Thomson et al., 2006). We compare the forecasts of the bargaining model with and without the UK included as a member of the EU. These comparisons indicate some of the pressures to which the remaining member states will need to respond in a post-Brexit EU.

The analysis then turns to network analysis. One of the main insights from network analysis is that mapping both the direct and indirect ties among actors in a political system is essential to understanding how the system works, both with respect to how those actors compete for influence, and how they cooperate to solve collective action problems (Feiock and Scholz, 2010; Knoke et al., 1996; Laumann and Knoke, 1987). The exit of any one of the actors from a network has obvious implications for the direct relations between that actor and the others 
with which it is connected. Exits also have less obvious implications for the indirect relations between the remaining actors. For instance, if an actor forms a bridge between otherwise unconnected or weakly connected pairs of other actors, then its removal could have significant consequences for the remaining actors far beyond the impact of its direct relations.

We use data from the Negotiations in the Council of the European Union (NCEU) project (Naurin, 2015; Naurin et al., 2017), which includes observations from 2018. The NCEU project has systematically surveyed member state representatives in each of the main working groups of the Council to identify the main cooperation partners of each of the states. Using this information, we assess the impact of the UK's exit on the direct and indirect relations among the remaining member states. We do so by calculating well-established measures of network centrality with and without the UK included in the network. These comparisons provide an indication of the changes in the cooperation network to which the remaining member states will need to adapt and are already adapting.

We integrate the spatial modelling and network analysis in two ways. First, we focus on the compensating measures that could be taken, and that to some extent already have been taken, by the remaining states most disadvantaged by Brexit. These disadvantaged states include Denmark, Ireland, the Netherlands and Sweden. The analysis reveals that these states are likely to become significantly less central in Council networks if they do not take compensating measures. The data from the spatial modelling approach enable us to identify the other states with which each of these Brexit-disadvantaged states shared similar policy positions in the past. The analysis shows that most of the Brexit losers have opportunities to compensate for the threatened reduction in centrality by forming new relationships with likeminded others. The analysis also shows that some of these new relationships have already been formed.

The second way in which we integrate the two approaches is by modelling the development of the network in one of the key committees, the Permanent Representatives 
Committee I (COREPER I), in 2018 using an Exponential Random Graph Model (ERGM). This model includes indicators of the expected effects of Brexit on each state's network centrality and an indicator of the similarity between states in terms of their previous policy positions as explanatory variables. This combination of network characteristics and policy affinity proved to be a powerful explanation of the evolution of cooperation networks in the Council in previous research (Huhe et al., 2018). The ERGM provides strong support for our argument that the cooperation network is adapting in response to the prospect of Brexit, and that states' policy affinity with each other is significantly shaping this adaptation.

\section{Spatial modelling}

One of the most extensive applications of the spatial model to everyday EU decision-making is found in the DEU dataset, which describes specific controversies that were raised by legislative proposals (Thomson et al., 2006, 2012). We focus on the 56 legislative proposals in the DEU dataset that were discussed in the period 2004-2008, when the EU consisted of 25 and then 27 member states after the enlargement to include Bulgaria and Romania in 2007. We use the DEU data from the post-2004 period because with the exception of Croatia, these data cover the same group of member states as the current and post-Brexit EU.

Although the information on member states' policy positions dates from 2004 to 2008, it offers an informative basis for assessing the impact of Brexit a decade later. Previous research that compared these data with earlier observations from the late 1990s and early 2000s found a large amount of stability in the content of the issues on the EU's agenda before and after the 2004 enlargement (Thomson, 2011: 51-78). Furthermore, to the extent that there was structure in the alignments of actors' positions, there was a stable divide between the Northern and Southern member states of the EU15 before and after the 2004 enlargement. The member states 
that joined in 2004 tended to take similar policy positions, again to the extent that the data exhibited stable structures in the alignments of actors' policy positions. Alongside these patterns, previous analyses of EU actors' policy positions using both DEU data and other sources have revealed persistent diversity, which we also expect to continue. Notwithstanding the abovementioned patterns, there are no fixed coalitions in the Council and alignments of states are typically formed on an issue-by-issue basis (Heyes-Renshaw and Wallace, 2006: 250). This has been the case in the past decades and is unlikely to change in a post-Brexit EU, which makes the post-2004 DEU data relevant to our inquiry. Moreover, Jacobs (2018: 103) concludes that there are 'unlikely to be fundamental shifts' in the EU's policy agenda following Brexit, with issues such as the 'development of the single market (notably the digital single market), further progress on the capital markets and banking unions, on the energy union and on fighting climate change' continuing to dominate. Nevertheless, we acknowledge the inherent uncertainty in assessing the impact of unfolding events. We cannot say for sure that the previous patterns will continue, or that the expected effects of Brexit will not be overshadowed by other major events.

The DEU dataset describes in detail the main controversial issues raised by the legislative proposals and the policy alternatives favoured the member states, the Commission and the European Parliament. The proposals raised on average between two and three main controversial issues, and there are 158 controversial issues in the post-2004 part of the dataset. Semi-structured interviews with key informants were conducted to describe the issues and the positions of the actors. Overall, more than 230 semi-structured interviews were held. Most of the interviewees were officials from the permanent representations or the primarily responsible officials in the Commission.

The dataset describes each of the controversial issues in a standard way to facilitate comparison across issues. Each controversial issue is described as a policy scale ranging from 
0 to 100 . The endpoints represent the most 'extreme' positions under consideration by the actors. The key informants placed intermediate positions on the scale to reflect the relative political distances between the alternatives. The key informants estimated the policy alternative most favoured by each of the actors at the outset of the negotiations, just after the introduction of the legislative proposal by the Commission. The policy scales are comparable in the sense that they reflect the range of the bargaining space on each controversy. In addition to estimating the positions of the actors, the informants also estimated the salience of the issues to the actors, again on a scale of 0 to 100 .

Figure 1 depicts one of the controversial issues described in the DEU dataset. The case refers to an issue raised by the proposal to extend the EU's emission trading scheme to aviation activities. The controversy concerned the extent to which the auctioning of carbon credits should be allowed. The positions ranged from those that opposed the introduction of auctioning (the 12 actors referred to on the left hand side of the figure) to those, including the European Parliament, that supported the maximum possible extension of the scheme. The actual decision outcome introduced a modest amount of auctioning, which our informants placed at position 30 on the policy scale. The UK favoured the introduction of somewhat more extensive auctioning, and was placed at position 50 on the policy scale to represent its position.

\section{$<$ Figure 1 here $>$}

The effect of the UK's exit on decision outcomes depends in part on the positions typically taken by the UK representation. Previous research indicates that the UK's positions generally favour lower levels of regulation and EU subsidies than those of most other states. Of the 158 issues raised by the post-2004 legislative proposals in the dataset, the UK took the same positions as Sweden on $52 \%$, as the Netherlands on $49 \%$ and as Ireland on $47 \%$, compared to 
the same positions as Italy on $32 \%$ and Spain on $32 \%$ too. These patterns determine the expected effects of Brexit on decision outcomes.

We apply a simple bargaining model of the legislative decision-making process, in which decision outcomes are reached through compromise and cooperative behaviour. This view of the decision-making process is encapsulated in the so-called compromise model, which is a first-order approximation of the famous Nash Bargaining Solution (NBS) (Achen, 2006: 98-101). When the disagreement outcome is extremely undesirable, the NBS can be represented in a very simple form. As the value that each of the actors attaches to the disagreement outcome becomes smaller and smaller, the NBS approaches a weighted average of actors' positions and at the limit, is identical to the weighted average. In Achen's (2006) operationalisation of the NBS, the weights assigned to actors' positions are the products of actors' capabilities and issue salience. ${ }^{1}$

The compromise model always generates a decision outcome that lies between the most extreme positions taken by any of the actors with capabilities. The exclusion of an actor from the compromise model always results in a prediction further from that actor's position as long as the excluded actor takes a position on the issue and has a salience score of greater than zero. In our analyses, having a position implies a positive salience score.

The analysis indicates that the departure of the UK leads to modest changes to the location of the decision outcomes on the majority of issues according to the logic of the compromise model. While the average magnitude of these changes is small, the results depicted in Figure 2 indicate that there are clear patterns. Each of the issues was examined to ascertain whether it involved choices between more or less integration, more or less regulation, and/or higher or lower subsidies. First, the outcomes predicted by the compromise model without the UK are not significantly more pro-integration than its predictions with the UK included. Second, the outcomes predicted without the UK are significantly more regulatory than the 
outcomes predicted with the UK. Third, the outcomes predicted without the UK involve significantly higher subsidies than the outcomes predicted with the UK.

\section{$<$ Figure 2 $>$}

There are also patterns concerning the location of the predicted outcomes in relation to other member states' positions. Outcomes without the UK will be somewhat closer to the positions of Spain and significantly further from the positions of Sweden, which accords with the observation that the UK's positions are generally furthest away from Spain and closest to Sweden. Finally, and by definition, decision outcomes without the UK are significantly further away from the UK's preferred positions.

In a supplementary analysis (presented in the Online appendix), we applied a different model of the EU's legislative process, and the results also suggest that removing the UK from the EU will have modest effects. We applied a model of the legislative process that is based on the EU's legislative procedures (Crombez, 1996; Tsebelis and Garrett, 2000). The results indicate that removing the UK rarely changes the process or outcomes fundamentally. The location of the pivotal position changes in only $8 \%$ of issues and the outcome changes in only $5 \%$ of issues. We present the results of the bargaining model, because this model outperformed procedural models in previous comparisons of the accuracy of their forecasts (Thomson et al., 2006).

\section{Network analysis}

Social capital theory makes clear why network relations are relevant to the capacity of a group of actors, in this case member states in the Council, to solve collective action problems. 
Networks are social structures that link actors to each other through multiple direct and indirect relationships (Coleman, 1988; Putnam, 1993; Schneider et al., 1997). These relationships are important partly for facilitating effective information flow, which is essential in the context of international cooperation where states are uncertain of each other's preferences (Keohane, 1984). Network relations are also channels through which actors monitor and sanction each other for violating social norms. The effectiveness of information flow and sanctioning mechanisms affects the trust that actors in a network have in each other, which is referred to as social capital. This in turn affects the ability of the network to solve collective action problems. Burt (2005) formalised the concepts of bridging and bonding ties from social capital theory. These concepts are closely related to the network measures of betweenness and closeness, which we examine below.

Information on the network relations among member state representatives was obtained through a survey of officials from the representations of all member states to the EU, as part of the NCEU project. The data have been used extensively in previous research (e.g. Häge and Naurin, 2013; Huhe et al., 2018; Naurin and Lindahl, 2010). The NCEU project surveyed representatives from all member states in eleven selected committees and working parties in the Council. The 'Council preparatory bodies' consist of more than 150 committees and working parties, where most of the negotiations take place. The eleven selected committees and working parties represent committees at different levels of the Council hierarchy and a broad range of policy areas. The policy areas included range from economic policy, agricultural policy, foreign and security policy, environmental policy, competition and internal market policy, to tax policy and justice and home affairs. ${ }^{2}$

In the surveys, the following question was asked: 'Which member states do you most often cooperate with within your working group, in order to develop a common position?'. Respondents were free to list other member states with which they cooperated, and typically 
mentioned between three and five others. On the basis of the respondents' answers to this question, we identify the network relations between member states. In our network analysis, a line connects two states if an official in at least one of the two states reported a cooperative tie when interviewed. Our theoretical definition of a cooperative network relationship is that it is reciprocal. However, we include directed relationships as an indication of the presence of a cooperative tie for measurement reasons. The survey question encourages respondents to name the most frequently used cooperation partners, rather than all cooperation partners. This is likely to bias the responses to the most salient cooperation partners. To overcome this limitation, we chose this inclusive operationalisation, which assumes that a tie exists if at least one of the two states reports it.

The concept of network relationships from social capital theory is broader than the operationalisation we use. While social capital theory refers to multiple direct and indirect relationships though which information flows, our operationalisation focuses more narrowly on cooperative relationships. These are likely to be a subset of a broader set of relationships through which information flows. Nonetheless, cooperative relationships are an especially important type, because they allow information to flow among actors that are embedded in trust relations with each other. This adds to the credibility of the information that is passed through these channels. Moreover, we do not argue that member states that do not cooperate with each other according to their answers to the NCEU survey cannot contact each other directly. Clearly all member states have diplomatic relations with each other. However, we argue that state representatives' answers to the NCEU survey contain valuable information on the depth of the relationships, and therefore on the ease of communication between each pair of permanent representations.

We focus on the three most recent surveys from the NCEU project, in 2012, 2015 and 2018, which are most relevant to assessing the impact of Brexit in terms of the pressure it will 
impose on the existing cooperation networks. The interviews were conducted by telephone and had response rates of $84 \%$ in 2012 (249 officials interviewed), 73\% in 2015 (225 officials interviewed) and $81 \%$ in 2018 (251 officials interviewed).

Figure 3 begins with a visualisation to illustrate the data we are using. It depicts the cooperation network of COREPER I in 2015 and 2018, i.e. before and after the Brexit vote. COREPER I is the pinnacle coordinating committee in the Council regarding legislative proposals across all core policy areas of the EU. A line connects two states if an official in at least one of the two states reported a cooperative tie when interviewed. The graphs indicate some instability in the UK's cooperative relationships between 2015 and 2018. It has five direct ties in both years. However, only the tie with the Czech Republic is constant. Between 2015 and 2018, the UK's ties with Cyprus, Denmark, Malta and Sweden are replaced by ties with Bulgaria, Ireland, the Netherlands and Spain. Based on this visual inspection, however, it is not clear whether the UK has in fact suffered from a loss of centrality in terms of its indirect ties. A visual inspection of the graphs mainly clarifies the direct impact of Brexit on the UK's direct ties, not its indirect effects.

\section{$<$ Figure 3 $>$}

We first focus on the likely consequences of Brexit on the centrality of the network positions of each of the other member states combining the information from 2012 and 2015. The reason for focusing on these waves is that in this first step of the analysis we wish to identify the likely effects of the UK's decision to leave the EU on the cooperative relations, rather than the emerging responses to it by the remaining EU members. The three most prominent measures of centrality in network analysis are degree centrality, closeness and betweenness. Degree centrality refers simply to the number of direct ties an actor has. Using this measure, we can 
only detect the impact of Brexit on states that had direct cooperative ties with the UK. Based on degree centrality, the countries that are expected to suffer most from Brexit are those that had direct relationships with the UK across a broad range of committees, notably Denmark, Ireland, the Netherlands, and Sweden. In contrast, for member states that had fewer direct ties with the UK, such as Austria, Belgium, Greece and Spain, the impacts of Brexit on their overall degree centrality are negligible.

Closeness and betweenness offer more refined and interesting measures of the impact of Brexit, and these are depicted in Figure 4. These measures are influenced by both direct and indirect ties, and therefore incorporate more information on the possible implications of Brexit on the remaining member states. Closeness centrality focuses on how close a member state is to all other members in the Council. The idea is that a member state is central if it can quickly interact with all other member states through a small number of links. The average of the shortest paths between each state and each of the other states is the most important part of the measure of closeness. The measure takes a higher value for actors that are generally closer to others. Note that if member state $i$ is connected to member state $j$ by both the UK and several other states, then $i$ 's shortest path length to $j$ does not necessarily increase as a result of the UK leaving. The measure of betweenness, by contrast, focuses on how central an actor is based on the frequency of its role as an intermediary between other actors. The key component of the measure of betweenness is the number of times a member state is a bridge along the shortest path between two other states.

We calculated the closeness and betweenness measures for each member state before and after removing UK from the 22 committee and working group networks, which were surveyed in 2012 and 2015. The significance tests noted in Figure 4 refer to the paired t-tests to assess the significance of the differences for each member state. 


\section{$<$ Figure 4 $>$}

The top of Figure 4 indicates that nine member states, including Sweden, the Netherlands and Ireland, are likely to be negatively and significantly affected by Brexit with respect to closeness. These countries rely on the UK as an intermediary to reach other member states in a range of committees.

We observe much larger variations in member states' betweenness than in their closeness scores. Member states rely heavily on a few intermediate players, in particular France, Germany and Poland, to reach other remote partners. The comparisons of the betweenness measures indicate that the mediating roles of these prominent players are further strengthened by the UK's exit from the EU Council. We find that eight countries' betweenness scores significantly increase by taking the UK out of the networks. Among these eight states, the positions of France, Germany and Poland are particularly strengthened.

\section{Integrating network analysis and the spatial model}

The analyses in this section integrate the network analysis and the spatial model to investigate the ways in which the remaining member states can and are already adapting to Brexit. We present two related analyses: the first focuses on the nine states that we expect to experience a significant fall in closeness centrality as a result of Brexit (Figure 4); and the second focuses on all remaining member states and how their network relations developed in 2018 in response to the prospect of Brexit.

The main question for our first analysis is to what extent the nine Brexit losers could form new cooperative relationships with other states, with which they were not directly linked in 2015 and with which they share similar levels of policy agreement, as they did with the UK, 
which would return them to at least the same level of centrality. In addition to identifying potential new relationships that would benefit the nine Brexit losers, we identify the new cooperative relationships that were actually formed in 2018. Our focus here is on COREPER I.

Figure 5 depicts the opportunities each of these nine states has to mitigate the negative impact of Brexit on its network centrality by forming new cooperative relationships with other states. We begin with the Czech Republic in Figure 5(a). The horizontal dashed line represents the Czech Republic's pre-Brexit level of centrality (measured by closeness), while the origin of the y-axis is the level to which the Czech Republic's centrality is expected to drop following Brexit before any actions by the Czech Republic in response to Brexit. The location of France, which is high on the y-axis and well above the horizontal dashed line, indicates that if the Czech Republic were to form a cooperative relationship with France, this would more than compensate for its loss of centrality due to Brexit. France is just to the left of the vertical dashed line, indicating that there was slightly less policy agreement between the Czech Republic and France as there was between the Czech Republic and the UK in the recent past. There are five countries located in the top-right corner of Figure 5(a), which include Portugal. New ties between the Czech Republic and any one of these states would bring the Czech Republic to a higher level of centrality than it had prior to the UK's exit. Moreover, the Czech Republic had a higher level of policy affinity with these five than it had with the UK in the recent past. New cooperative relationships were formed in 2018 between the Czech Republic and the five circled member states: Belgium, Germany, Portugal, Malta and Estonia.

\section{$<$ Figure 5 $>$}

We briefly highlight the main findings for each of the other eight states: 
Denmark (Figure 5(b)) has fewer opportunities to compensate the loss in centrality compared to the Czech Republic. The top-right corner of the graph for Denmark is empty, which means that there is no other state with which Denmark had more policy agreement than it had with the UK, and with which it could form a new tie that would compensate for the reduction in its centrality as a consequence of Brexit. The best option for Denmark is to cultivate new relationships with France, Greece, Ireland and Belgium. In fact, new cooperative relationships were formed between Denmark on the one hand and Ireland and Belgium on the other in 2018. Finland (Figure 5(c)) should prioritise the cultivation of new cooperative relationships with Portugal, Greece, Belgium and Ireland. In fact, in 2018, a new cooperative relationship was formed between Finland and Ireland.

Ireland (Figure 5(d)) should prioritise Belgium. New links with Greece, Denmark, Finland and the Netherlands would also compensate for Brexit, and Ireland has had only somewhat less policy affinity with these countries than it had with the UK. The 2018 data indicate that new relationships emerged with Denmark, the Netherlands and Finland.

Lithuania (Figure 5(e)) and Latvia (Figure 5(f)) have many opportunities to form new relationships that would more than compensate for Brexit with states with which they were at least as like-minded as they were with the UK. Only Latvia and Sweden formed a new tie in 2018.

Malta (Figure 5(g)) too has many opportunities to form compensating new links. The three Baltic states and Poland stand out as states that could bring Malta up to a higher level of centrality than Malta had before Brexit. Moreover, Malta agreed more with these states on policy issues than it did with the UK in the recent past. The data show seven new ties involving Malta in 2018.

The Netherlands (Figure 5(h)) and Sweden (Figure 5(i)) are in similar positions to each other in that there are no other states with which they are currently not linked, with which they agreed 
as much as they did with the UK, and with which a new relationship would bring them back to the same level of centrality or higher as they had prior to Brexit. However, for both the Netherlands and Sweden, forming a new cooperative relationship with each other would be advantageous. Indeed, the 2018 data indicate that a new tie emerged between the Netherlands and Sweden among several other new cooperative relationships.

Our analysis so far has indicated that the nine likely Brexit losers have different opportunities for compensating the loss in centrality that Brexit may bring, and that some of these opportunities were taken in 2018.

We now turn to the second analysis that integrates the network and spatial modelling perspectives, which takes the form of an ERGM of the 2018 COREPER I cooperation network. The ERGM, also known as the $p^{*}$ model (Robins et al., 2007), was introduced to model complex dependencies in a given network. It allows us to estimate the effects of structural properties of the network and covariates associated with individual nodes, in our case member states, on the probability that ties exist between nodes. The structural properties include density (overall connectivity in the network), homophily (such as policy affinity between states), and transitivity. Transitivity is the commonly found pattern where friends of friends are friends. The relevant covariates associated with individual member states are the expected centrality losses (in terms of degree, closeness and betweenness) as a result of Brexit. The ERGM can be written as follows,

$$
\operatorname{Pr}\left(\mathbf{Y}=y_{i j}\right)=\frac{1}{\kappa} \cdot \exp \left\{\sum \eta_{A} g_{A}(y)\right\}
$$

where $y_{i j}$ denotes a tie in the cooperation network $\mathbf{Y}$, and $\kappa$ is the normalising constant. $g_{A}(y)$ represents our model terms and $\eta_{A}$ is the corresponding coefficient.

We focus on three types of model terms (i.e. $g_{A}(y)$ ): transitivity, homophily, and nodal attributes of expected network loss. First, transitivity refers to the network mechanism that two member states are more likely form a cooperative tie if they share common partners. 
Transitivity not only helps explain how cooperation can move beyond simple dyadic reciprocity, but also is the driving mechanism behind dense local clusters, which are common in various cooperation networks. Considering the fact that two countries could share multiple common partners and the marginal impacts of additional common partners are likely to diminish, we use the geometrically weighted edge-wise shared partner distribution (GWESP), rather than the raw numbers of triangles (Hunter, 2007). This allows us to assign more weights to dyads with few common partners. Second, we expect homophily in the form of policy affinity to affect how states form cooperative ties, as found in previous research using similar datasets (Huhe et al., 2018). Finally, we estimate the effects of each state's expected changes in centrality as a result of Brexit. We include each state's expected changes in centrality in terms of degree, closeness, and betweenness centrality. We first estimate a baseline model (1) with GWESP, and then we add the homophily term of policy affinity (model 2), nodal attribute terms of expected degree loss (model 3), closeness loss (model 4), and betweenness loss (model 5), respectively. A saturated model (6) incorporates all these terms. Finally, we estimate a full model (7) without degree loss, which is correlated with closeness loss. ${ }^{3}$

\section{$<$ Table 1 $>$}

Table 1 presents the models. ${ }^{4}$ Models 1 and 2 confirm the earlier findings of Huhe et al. (2018) by showing that both shared partners (i.e. transitivity as measured by GWESP) and policy affinity (i.e. homophily) facilitate the formation of cooperative ties between EU member states. ERGM coefficients are similar to those of logistic regression, indicating the log-odds of tie formation. Taking model 2 as an example, for a pair of nodes with no shared partner and policy affinity of zero, the log-odds of a tie between them is $-7.08+(1.86 \times 0)+(9.59 \times 0)=$ -7.04 , and its corresponding probability is $\frac{\exp (-7.08)}{1+\exp (-7.08)}=0.0008$. In contrast, if the policy 
affinity score is 0.5 , the probability of a cooperative tie is 0.092 ; when the policy affinity reaches 1 , the probably of a tie increases to 0.925 .

More importantly, models 3, 4 and 5 show that the effects of expected centrality losses from Brexit have induced significant changes to patterns of cooperation. Model 3 shows that degree loss is positively and significantly associated with formation of cooperative ties. This suggests that controlling for clusters (i.e. GWESP) and policy affinity, the UK's direct partners in the 2015 COREPER I network were more likely to form cooperative ties in 2018. Specifically, states that were not linked to the UK in 2015 have a probability of 0.084 of forming cooperative ties (assuming zero shared partners and a policy affinity score of 0.5 ), while similar states that were linked to the UK in 2015 have a probability of 0.149 of forming cooperative ties. In other words, the UK's direct partners in 2015 are significantly more active than nonUK partners in the 2018 COREPER I network. Model 4 points to the significant and positive impact of loss in closeness. Unlike degree, closeness captures connectivity by taking both direct and indirect relationships into account. The results thus suggest that countries that expected losses in closeness were more likely to forge cooperative ties in 2018 . In model 5, we find that betweenness gain significantly and positively affects tie formation. As revealed earlier, Brexit is expected to elevate the importance of remaining brokering countries such as France, Germany, and Poland. Our ERGM analysis confirms this; countries that are expected to become more central (in betweenness centrality) following Brexit are more likely to be connected to other countries in 2018. The expected gain in betweenness makes these states more attractive cooperation partners. Other countries, including those that are expected to suffer losses in centrality from Brexit, are likely to seek ties with these increasingly important brokers. Model 6 incorporates all three centrality measurements. While degree loss and betweenness gain remain statistically significant, closeness loss does not. One reason is that measurements of centrality, degree and closeness centralities are correlated (i.e. collinearity). We thus drop 
degree loss in the full model and find significant impacts of both closeness loss and betweenness gain.

\section{Conclusions}

Our findings indicate some of the pressures that Brexit will impose on the EU, characteristics that will help the EU to meet these challenges, and emerging behaviour in response to the prospect of Brexit. Our analyses suggest that Brexit will put pressure on decision outcomes to be somewhat more regulatory rather than liberal in terms of levels of market intervention, and related to this, somewhat more inclined to provide subsidies. A corollary is that there will be pressure on decision outcomes to be somewhat closer to the policy positions typically taken by Spain and further away from the positions taken by Sweden. This is due to the fact that the UK has usually been on the free market side of controversies concerning the level of regulatory intervention, and generally an ally of Sweden, among other states, on a substantial proportion of controversial issues.

Some member states face particularly significant challenges as a consequence of Brexit. The mediating roles of the remaining larger member states, in particular France, Germany and Poland, are likely to be enhanced by Brexit. Some smaller and medium sized states - Denmark, Ireland, the Netherlands and Sweden - confront the toughest challenges in maintaining their influence in the Council. These are the states with the closest network ties to the UK, and with the most similar policy positions.

The pressures on the EU imposed by Brexit will be ameliorated by the lack of structure in the policy positions of member states. The consequence of this lack of structure is that taking any one of the actors out of the process seldom leads to radically different decision outcomes across a range of issues in terms of more or less integration or regulation, or higher or lower 
subsidies. While previous research identified some regularities in the policy positions taken by member states, these regularities occur in a minority of cases. This means that states which agree with each other on some issues disagree with each other on other issues. This overall lack of structure in the positions of member states has been found in previous qualitative and quantitative research (Heyes-Renshaw and Wallace, 2006: 250; Thomson, 2011). This lack of structure also supports the dominant mode of cooperative bargaining in the EU, where decision outcomes are most accurately modelled as compromises that take into account the policy positions of all actors (Achen, 2006).

Another characteristic of the EU's political system that ameliorates the impact of Brexit is the stock of network capital held by member states and member states' ability to build new network capital. This refers to the density of direct and indirect cooperative relationships among to the remaining EU27 states. Scholarship in the field of network analysis has shown that informal ties are essential to how actors compete for influence and how they solve collective action problems (e.g. Feiock and Scholz, 2010; Laumann and Knoke, 1987). Our analysis of the most recent network data from 2018 indicates that the remaining EU27 are already building new network capital. Those states that are directly and negatively impacted by Brexit are most active in forming new ties, and the large states, whose mediating roles are expected to grow, are gaining new ties. These new informal structures are likely to endure regardless of the form and timing of the UK's eventual departure from the EU, which is uncertain at the time of writing. The findings indicate how informal institutions, of which network ties are an example, are constructed by the same actors that they enable and constrain. By being aware of and actively responding to the pressures that Brexit will bring, the EU has the capacity to adapt successfully. 


\section{References}

Achen, Christopher H. 2006. Institutional Realism and Bargaining Models. In Robert Thomson, Frans. N. Stokman, Christopher H. Achen and Thomas König (eds.) The European Union Decides. Cambridge: Cambridge University Press, pp. 86-123.

Armstrong, Kenneth A. 2018. Regulatory alignment and diversity after Brexit. Journal of European Public Policy 25(8): 1099-1117.

Bueno de Mesquita, Bruce and Frans N. Stokman. (eds.) 1994. European Community Decision Making: Models, Applications and Comparisons. New Haven: Yale University Press.

Burt, Ronald. 2005. Brokerage and Closure: An Introduction to Social Capital. New York: Oxford University Press.

Coleman, James. 1988. Social Capital in the Creation of Human Capital. The American Journal of Sociology 94: S95-S120.

Crombez, Christophe. 1996. Legislative Procedures in the European Community, British Journal of Political Science 26: 199-228.

Feiock, Richard C., and John Scholz. eds 2010. Self-Organizing Governance: Collaborative Mechanisms to Mitigate Institutional Collective Action Dilemmas. New York: Cambridge University Press.

Gamble, Andrew. 2018. Taking back control: The political implications of Brexit. Journal of European Public Policy 25(8): 1215-1232.

Häge, Frank M. and Naurin, Daniel. 2013. The effect of co-decision on Council decisionmaking: Informalization, politicization, and power. Journal of European Public Policy 20(7).

Hunter, David R. 2007. "Curved Exponential Family Models for Social Networks." Social Networks 27: 216-30.

Hayes-Renshaw, Fiona and Helen Wallace. 2006. The Council of Ministers, 2nd edition. Basingstoke: Palgrave Macmillan.

Huhe, Narisong, Daniel Naurin and Robert Thomson. 2018. The evolution of political networks: Evidence from the Council of the European Union. European Union Politics 19 (19): 25-51.

Jacobs, Francis B. 2018. The EU after Brexit: Institutional and Policy Implications. Cham: Palgrave Macmillan.

Keohane, Robert O. 1984. After Hegemony: Cooperation and Discord in the World Political Economy. Princeton: Princeton University Press.

Knoke, David, Franz U Pappi, Jeffrey Broadbent and Yutaka Tsujnaka. 1996. Comparing Policy Networks. Labor Politics in the US, Germany and Japan. Cambridge: Cambridge University Press.

Krotz, Ulrich and Joachim Schild. 2018. Back to the future? Franco-German bilateralism in Europe's post-Brexit union. Journal of European Public Policy 25(8): 1174-1193.

Laumann, Edward O. and David Knoke. 1987. The Organizational State: Social Choice in National Policy Domains. Madison: University of Wisconsin Press.

Möller, Almut and Tim Oliver eds. 2014. The United Kingdom and the European Union: What Would a 'Brexit' Mean for the EU and Other States Around the World? Berlin: German Council on Foreign Relations (DGAPanalyse 16), available at https://dgap.org/en/article/getFullPDF/25763 (accessed day month year).

Naurin, Daniel. 2015. Generosity in intergovernmental negotiations: The impact of state power, pooling and socialization in the Council of the EU. European Journal of Political Research 54(4): 726-44. 
Naurin, Daniel, Johansson Markus and Lindahl Rutger. 2017. The Cooperation and Negotiations in the Council of the European Union Dataset. Centre for European Research at the University of Gothenburg (CERGU).

Naurin, Daniel and Rutger Lindahl. 2010. Out in the Cold? Flexible Integration and the Political Status of Euro Opt-Outs. European Union Politics 11(4) 485-509.

Oliver, Tim. 2016. European and international views of Brexit. Journal of European Public Policy 23(9): 1321-1328.

Putnam, Robert D. 1993. Making Democracy Work. Princeton, NJ: Princeton University Press.

Robins, Garry, Pip Pattison, Yuval Kalish, and Dean Lusher. 2007. An Introduction to Exponential Random Graph $\left(p^{*}\right)$ Models for Social Networks. Social Networks 29: 17391.

Schneider, Mark, Paul Teske, Melissa Marschall, Michael Mintrom and Christine Roch. 1997. Institutional Arrangements and the Creation of Social Capital: The Effects of Public School Choice. American Political Science Review 91(1): 82-93.

Steenbergen, Marco R. and Tomasz Siczek. 2017. Better the devil you know? Risk-taking, globalization and populism in Great Britain. European Union Politics 18(1): 119-136.

Steunenberg, Bernard. 1994. Decision-Making under different Institutional Arrangements: Legislation by the European Community. Journal of Theoretical and Institutional Economics 150: 642-69.

Thomson, Robert. 2011. Resolving Controversy in the European Union: Legislative DecisionMaking Before and After Enlargement. Cambridge: Cambridge University Press.

Thomson, Robert, Javier Arregui, Dirk Leuffen, Rory Costello, James Cross, Robin Hertz, and Thomas Jensen. 2012. A new dataset on decision-making in the European Union before and after the 2004 and 2007 enlargements (DEUII). Journal of European Public Policy 19 (4): 604-622.

Thomson, Robert, Frans N. Stokman, Christopher H. Achen and Thomas König. Eds. 2006. The European Union Decides. Cambridge: Cambridge University Press.

Tsebelis, George, and Geoffrey Garrett. 2000. Legislative Politics in the European Union. European Union Politics 1 (1): 9-36. 
Figures and tables

What are the positions of the actors regarding the auctioning of carbon credits?

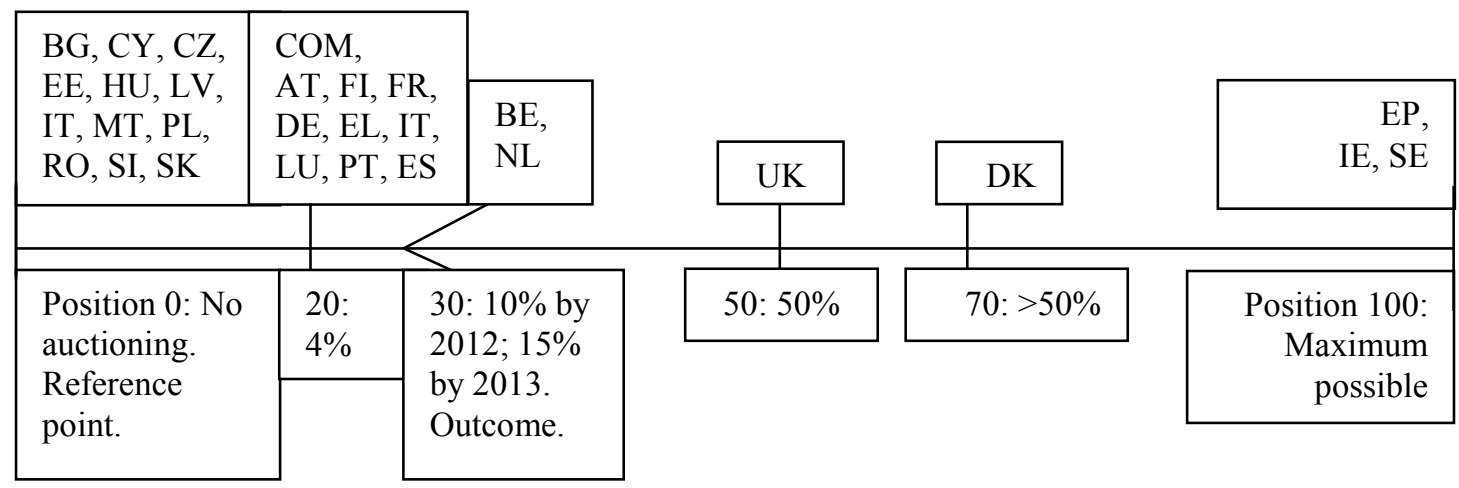

Figure 1. One of the main controversial issues raised by proposal on the inclusion of aviation in the emission trading scheme Note: Proposal COD/2006/304. COM: Commission; EP: European Parliament; AT: Austria; BE: Belgium; BG: Bulgaria; CY: Cyprus; CZ: The Czech Republic; DK: Denmark; EE: Estonia; FI: Finland: FR: France; DE: Germany; EL: Greece; HU: Hungary; IE: Ireland; IT: Italy; LV: Latvia; LT: Lithuania; LU: Luxembourg; MT: Malta; NL: The Netherlands; PL: Poland; PT: Portugal; RO: Romania; SI: Slovenia; SK: Slovakia; ES: Spain; SE: Sweden; UK: The United Kingdom. 


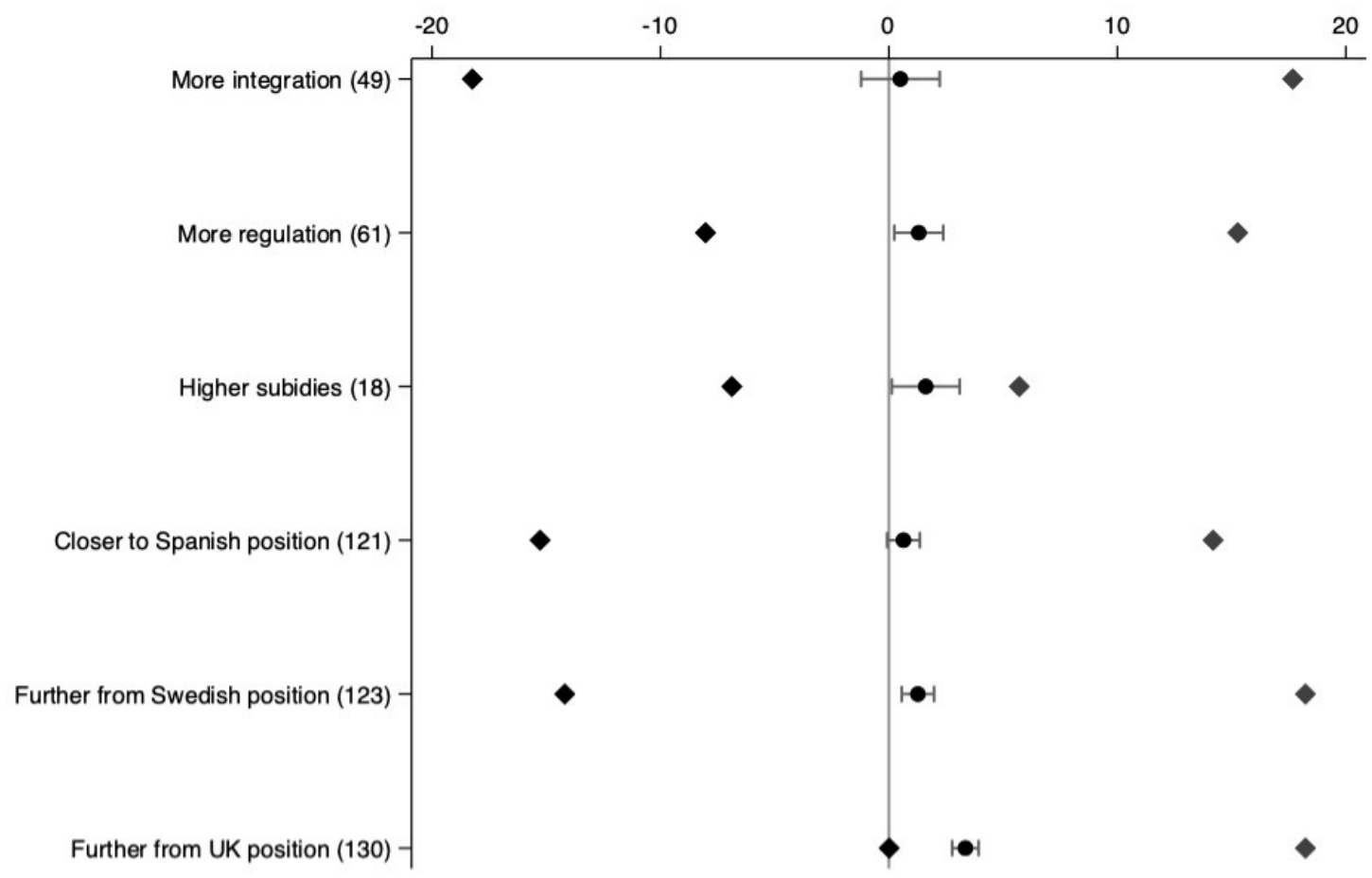

Figure 2. The directional impact of Brexit on decision outcomes according to the bargaining model

Note: Circles refer to the average impact of Brexit, bars indicate the $95 \%$ confidence intervals, and diamonds refer the minimum and maximum values. Numbers in parentheses are the numbers of relevant post-20014 issues from the DEU II dataset. 

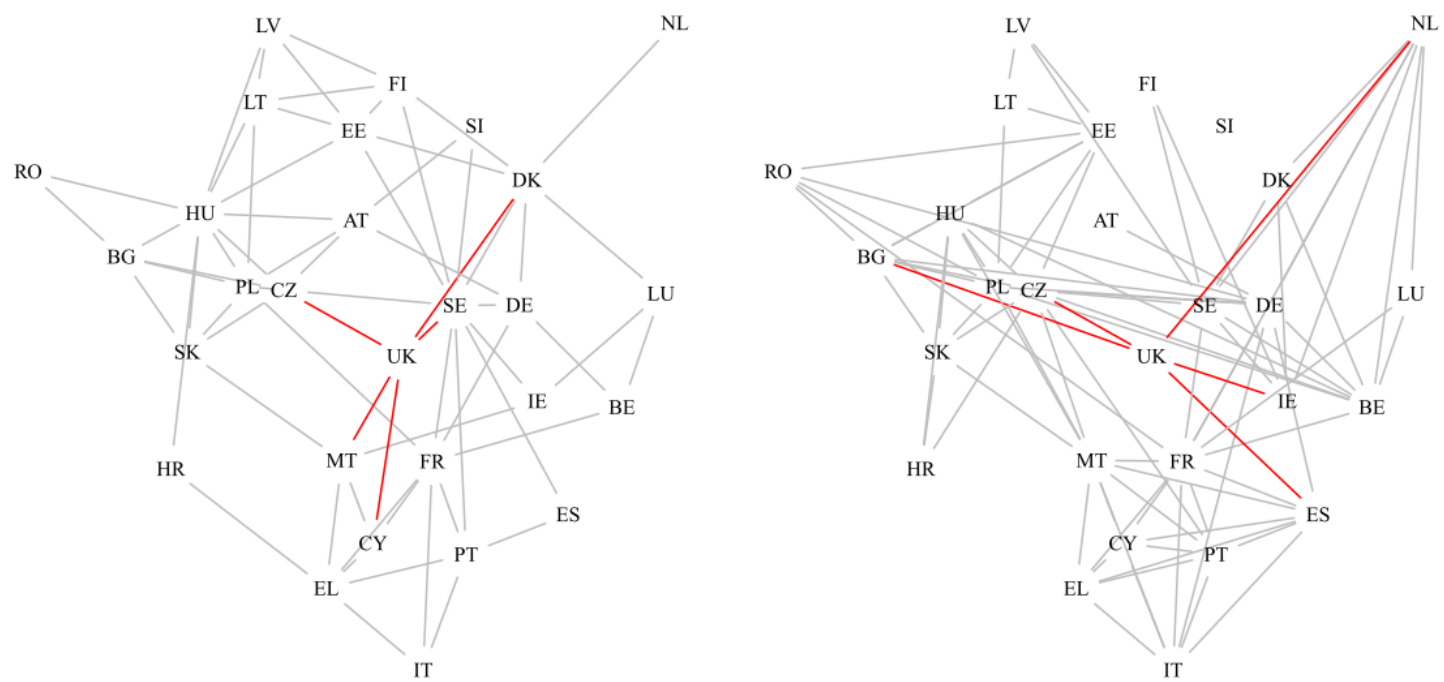

Figure 3: Cooperation network in COREPER I in 2015 and 2018 compared

Note: Lines indicate the presence of a cooperative relationship between the two connected states as indicated by key informants' responses in the NCEU survey in 2015 (left) and 2018 (right). Excludes Croatia 


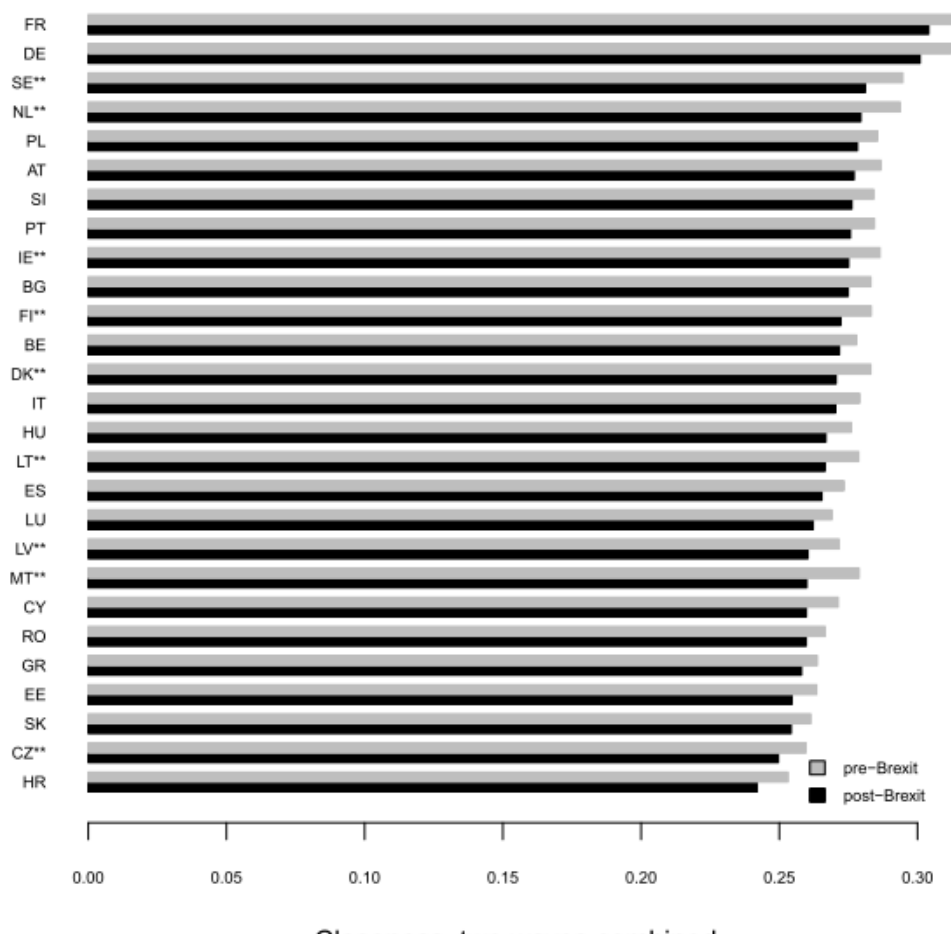

Closeness, two waves combined

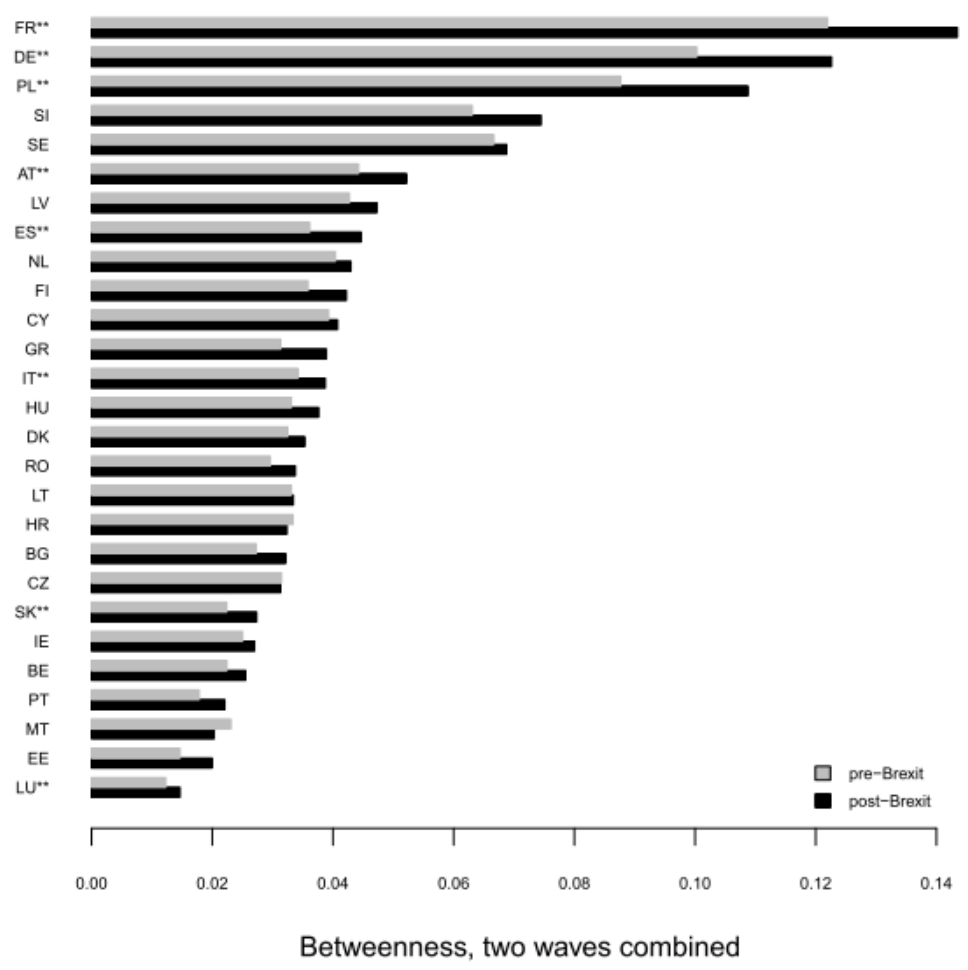

Figure 4: Country-based comparison of changes in closeness and betweenness Note: Based on NCEU surveys in 2012 and 2015 combined. $* * p<0.05$ 
(a) CZ, 5 new ties in 2018

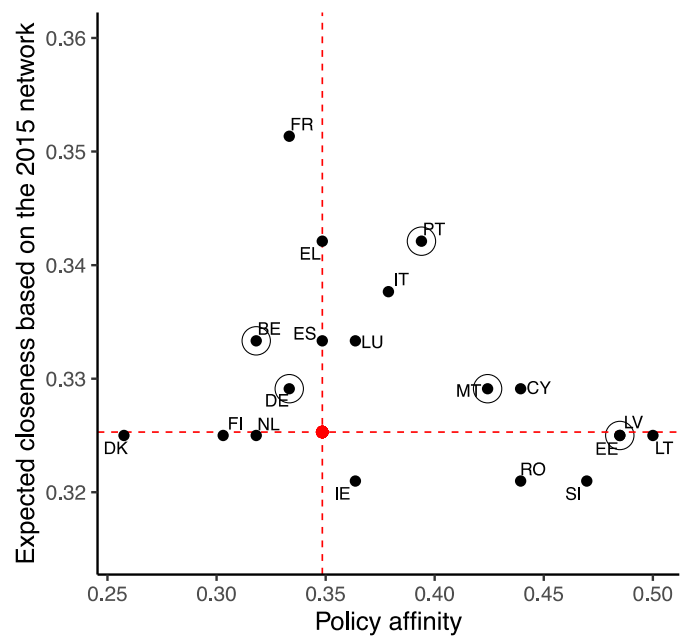

(c) FI, 1 new ties in 2018

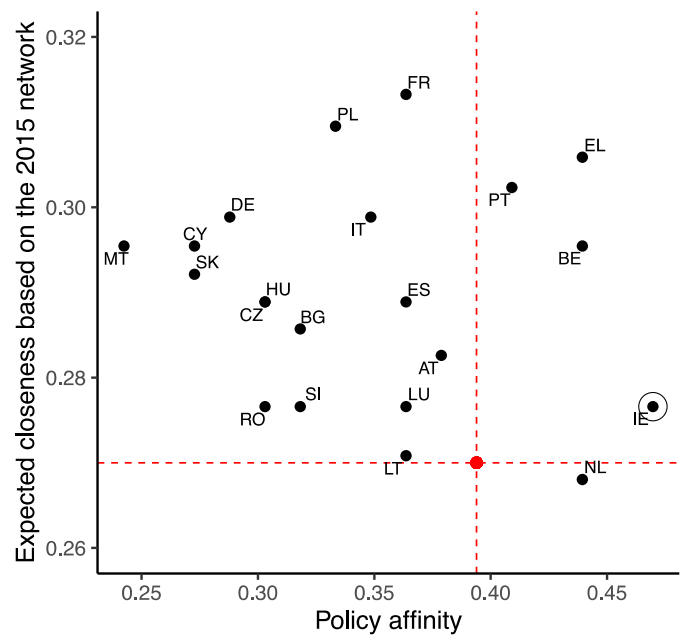

(e) LT, no new ties in 2018

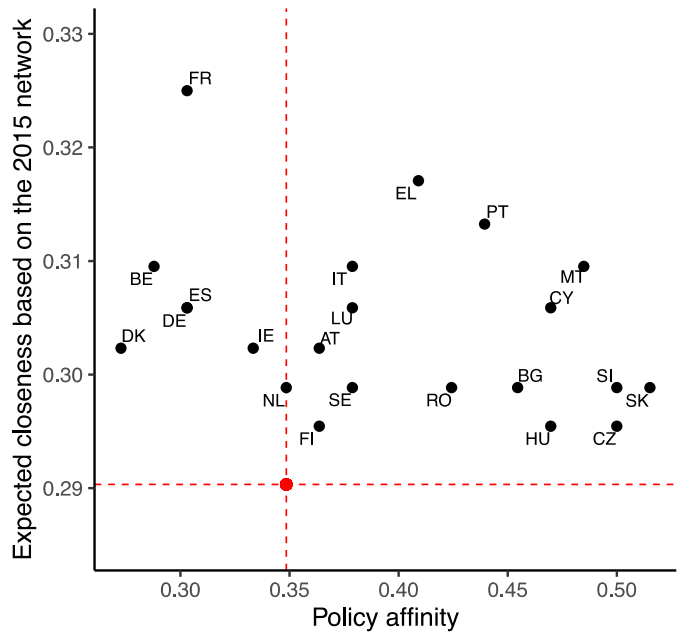

(b) DK, 2 new ties in 2018

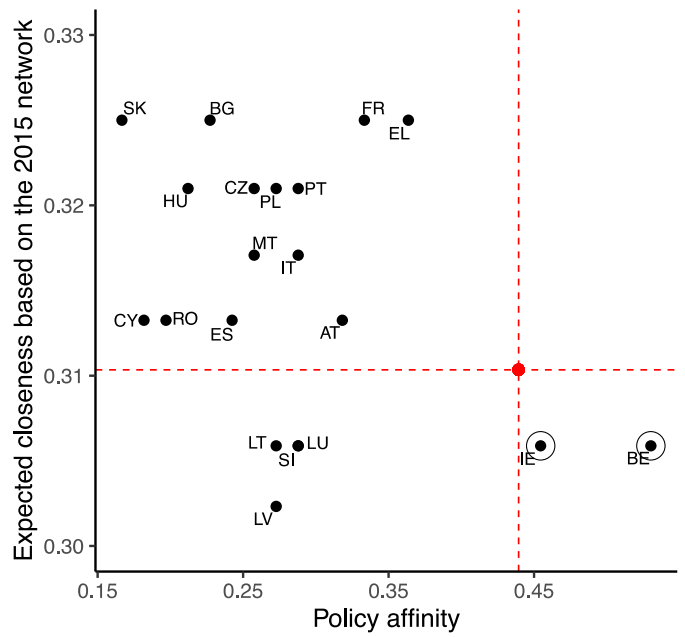

(d) IE, 3 new ties in 2018

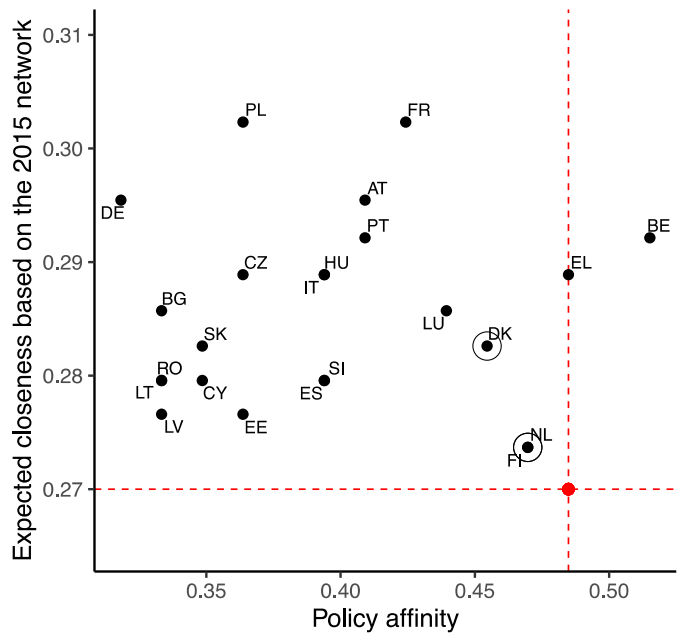

(f) LV, 1 new ties in 2018

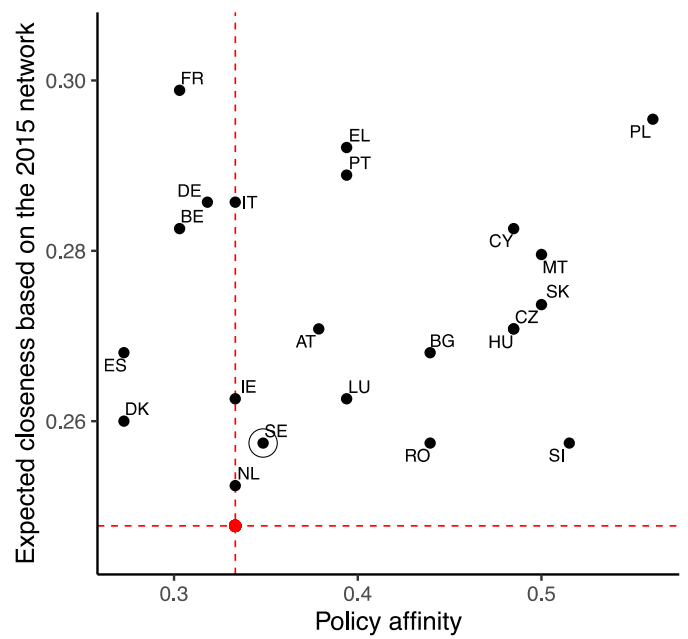

Figure 5. The expected impact of Brexit and new relationships in COREPER I in 2018

Note: Horizontal dashed lines indicate the pre-Brexit level of closeness for the focus state in 2015. The origin of the y-axis is the expected post-Brexit level of closeness. Vertical dashed lines indicate the proportion of issues on which the focus state and the UK had the same policy positions. Member states in each graph are those with which the focus state did not have a tie in 2015. The circled member states are those with which a new tie was formed in 2018. 
(g) MT, 7 new ties in 2018

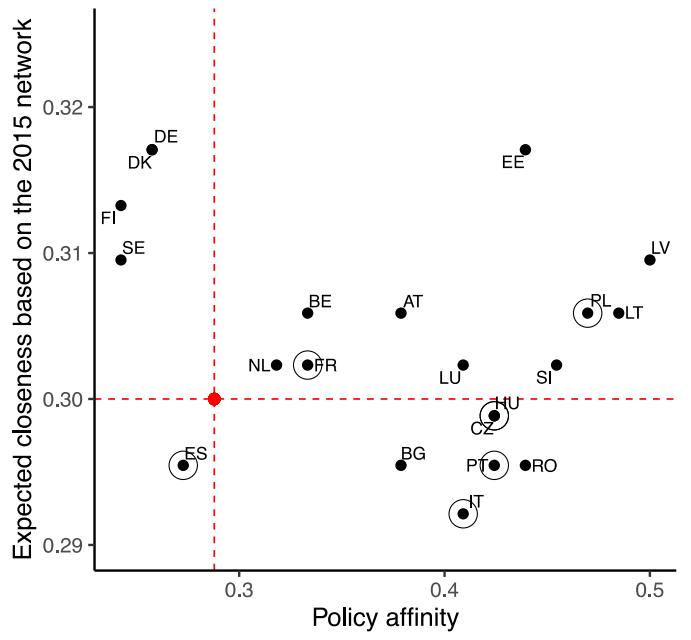

(i) SE, 4 new ties in 2018

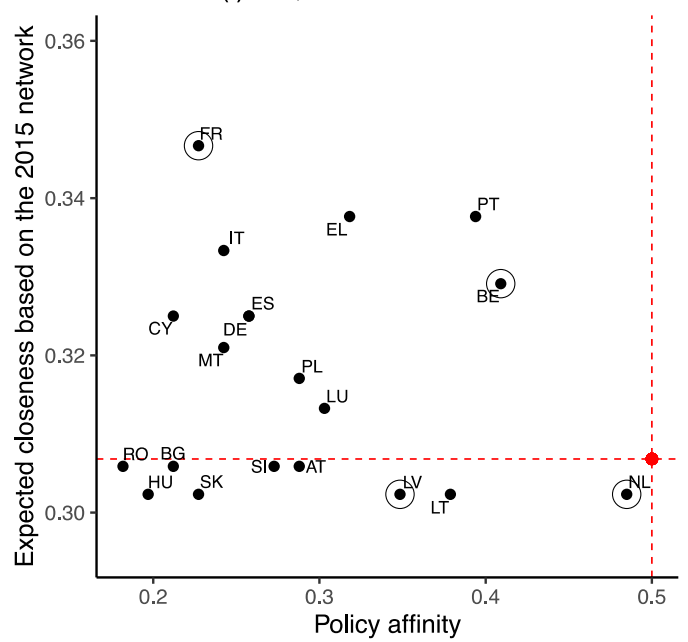

(h) NL, 6 new ties in 2018

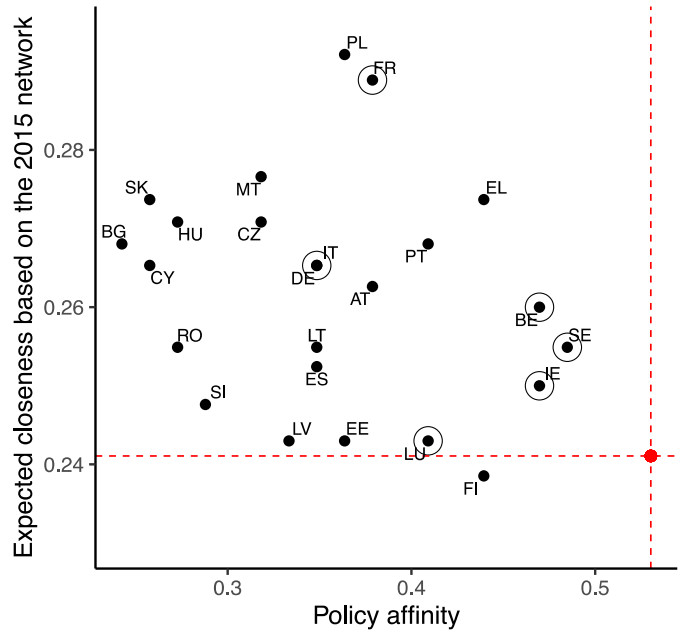

Figure 5 (continued). The expected impact of Brexit and new relationships in COREPER I in 2018 
Table 1. ERGM Analysis of COREPER I in 2018

Dependent variable:

COREPER I in 2018, $y_{i j}=\mathbf{Y}$

\begin{tabular}{lccccccc} 
& $(1)$ & $(2)$ & $(3)$ & $(4)$ & $(5)$ & $(6)$ & $(7)$ \\
\hline Edges & $-3.48^{* * *}$ & $-7.08^{* * *}$ & $-7.55^{* * *}$ & $-7.36^{* * *}$ & $-7.44^{* * *}$ & $-8.57^{* * *}$ & $-8.37^{* * *}$ \\
& $(0.74)$ & $(0.98)$ & $(0.99)$ & $(1.00)$ & $(1.01)$ & $(1.11)$ & $(1.08)$ \\
GWESP & $1.99^{* * *}$ & $1.86^{* * *}$ & $1.80^{* * *}$ & $1.82^{* *}$ & $1.75^{* *}$ & $1.64^{* *}$ & $1.65^{* *}$ \\
& $(0.69)$ & $(0.71)$ & $(0.70)$ & $(0.72)$ & $(0.69)$ & $(0.74)$ & $(0.74)$ \\
Policy affinity & & $9.59^{* * *}$ & $10.33^{* * *}$ & $9.94^{* * *}$ & $10.27^{* * *}$ & $12.04^{* * *}$ & $11.49^{* * *}$ \\
& & $(1.68)$ & $(1.75)$ & $(1.69)$ & $(1.81)$ & $(1.91)$ & $(1.84)$ \\
Degree loss & & & $0.64^{* * *}$ & & & $0.94^{* *}$ & \\
& & & $(0.23)$ & & & $(0.44)$ & \\
Closeness loss & & & & $28.30^{*}$ & & 11.65 & $68.54^{* * *}$ \\
& & & & $(16.10)$ & & $(33.55)$ & $(20.22)$ \\
Betweenness gain & & & & & $18.81^{* * *}$ & $30.19^{* * *}$ & $31.13^{* * *}$ \\
& & & & & $(7.03)$ & $(8.05)$ & $(8.12)$ \\
\hline AIC & 347.08 & 309.39 & 303.99 & 308.37 & 303.70 & 291.36 & 294.07 \\
BIC & 354.65 & 320.74 & 319.13 & 323.51 & 318.84 & 314.07 & 312.99 \\
Log Likelihood & -171.54 & -151.70 & -148.00 & -150.19 & -147.85 & -139.68 & -142.03 \\
\hline Note: ${ }^{* * *} p<0.01,{ }^{* *} p<0.05,{ }^{*} p<0.1$. & & & & & \\
GWEP: Geometris & & & & & & &
\end{tabular}

GWESP: Geometrically weighted edge-wise shared partner distribution. 
${ }^{1}$ We operationalise capabilities as informal bargaining power and use as a proxy measure the $\log$ of member states' population sizes (in millions plus one). This measure is highly correlated with previous expert judgements of the relative power of states in which large states have more power than small and medium states, but small and medium states are overrepresented relative to their population sizes. Although we consider this measure to be more appropriate given our concept of capabilities, we obtain the same results using voting power indicies as proxy measures.

${ }^{2}$ The eleven committees are: COREPER I, COREPER II, the Political Security Committee (PSC), the Special Committee on Agriculture (SCA), the Economic Policy Committee (EPC), the Politico-Military Group (PMG), the Working Party on Tax Questions, the Coordinating committee in the Area of Police and Judicial Cooperation in Criminal Matters (CATS), the Working Party on Agricultural Questions, the Working Party on Competitiveness and Growth, and the Working Party on the Environment.

3 The edges term in the ERGM is similar to the constant term in other statistical models. It captures the overall connectivity of a network. In the null model that includes only the edges term, its coefficient is -1.12 . This is the average log-odds that two nodes are connected. Its corresponding probability, $\frac{\exp (-1.12)}{1+\exp (-1.12)}=0.246$, thus equals the density of the network, $\frac{80 \times 2}{26(26-1)}=0.246$. In other words, on average a node in this network has a probability of 0.246 to form a cooperative tie with another node.

4 The results of goodness-of-fit analyses are presented in the Online appendix. 